\title{
Nutritional Study of an Apple Orchard as Endemically Affected by Bitter-Pit
}

\author{
Val, J., Gil, A., Aznar, Y., Monge, E., Blanco, A.
}

Estación Experimental de Aula Dei (CSIC). PO BOX 202. Zaragoza 50080 ES : Spain

KeyWords: bitter pit; calcium deficiency; apples; plant nutrition

\begin{abstract}
Bitter-pit has been related to nutritional fruit unbalances, especially to calcium deficiency. In order to elucidate the nutritional and physiological processes that lead to a development of bitter-pit, a nutritional study of a Golden Smoothee/M9 apple orchard, endemically affected by bitter-pit has been carried out. An evaluation of bitter-pit incidence at harvest showed that only few apples had symptoms, but following two months under cold storage, more than $80 \%$ were affected. Mineral elements in leaves and fruits were analysed. As bitter-pit is associated with fruit size, the diameter and fresh and dry weight of fruits were recorded regularly, and the values fitted to sigmoid equation of growth, to calculate final size and maximum fruit growth rate. In terms of mineral nutrition, Nitrogen relates linearly to calcium and the ratio $\mathrm{K} / \mathrm{Ca}$ in fruits increases along the season reaching a value of 41 at harvest time. A good correlation between leaf chlorophyll and fruit soluble carbohydrates was found.
\end{abstract}

\section{Introduction}

As stated by Ferguson, I.B. (1989), apples are still being produced, which are just as susceptible to bitter-pit as that grown 100 years ago. Bitter-pit appears as slight indentation in the skin, usually toward the calyx end of the fruit. These areas turn brown, and soft desiccated tissue develops in the flesh immediately beneath the spots. Bitter-pit may develop while the fruit is still on the tree, but usually develops in storage or after fruit is taken from storage and kept for a few days at room temperature (Shear, C.B. (1980)). In fact, bitter-pit is a pathology that causes serious economic losses in the apple production. During the last thirty years, exhaustive investigations have been carried out with the objective of alleviating the problem. Most of researches agree, that a good value of soil $\mathrm{pH}$ (6.5-7), an appropriate pruning methodology, including the summer pruning (Preston, A.P. (1974) and a favorable water régime, especially in the first phases of the season (Failla, O. (1990)) are helpful to alleviate the bitter-pit problem. In addition, excessive fruit sizes increase the incidence of the disorder (Volz, R.K. (1993)). However, the causes promoting the appearance of bitter-pit still have not been completely established (Monge, E. (1995)). 
At present, three main theories are proposed. The first of them suggests that bitter-pit is produced by a calcium deficiency or by an excess of potassium in the fruit (Tomala, K. (1997a)). In this way, it is always interesting to analyze the ratio K/Ca (Marcelle, R.D. (1993)), and it is not recommended to store fruits with a value of the ratio higher than 36 (Tomala, K. (1997b)). Curtis, D. (1990) suggest that a movement of the water soluble forms of $\mathrm{Ca}$ takes place from the fruit toward the adjacent leaves, causing the development of some physiological disorders.

The second theory proposes that during the photosynthetic process which basically consists on the fixation of the carbon $\left(\mathrm{CO}_{2}\right)$ and the inorganic nutrients absorbed by the roots, the leaves form the essential compounds, but also toxic substances as oxalic and citric acids (Steenkamp, J. (1983)). Most of the living organisms also produce them during their biological processes; however, they possess means to inactivate them under solid or liquid forms. The plants have none of these mechanisms, remaining as the sole alternative the metabolism of these noxious compounds through crystallization or formation of calcium complex substances (Steenkamp, J. (1980)). The formation of these complexes is a physical reaction, without liberation of energy, and it is the most effective way to neutralize these acids. The excretion of the excess of undesirable organic acids is made in the terminal phase, through the vascular bundles that are located mainly in the calyx of the apple. When the quantity of dissolved calcium is not enough to neutralize those mentioned acids. The death of the cells takes place in certain parts of the apple, producing the dark stains known as Bitter Pit lesions. This way, the direct relationship is appreciated between the lack of calcium and Bitter Pit incidence.

Finally, in the third theory Saure, M.C. (1996) intends that the causing factor of the bitter-pit is the high concentration of gibberellins in the fruit in advanced stages of the season. This is probably owed, to an excessive root activity. The consequences of the high levels of GA's cause increments of the cellular permeability in the fruit areas near to the vascular bundles, causing, in turn, a sensitization to the post-harvest water stress. This water stress, could trigger the mechanisms of the development of the bitter-pit, if the primary factor that causes the susceptibility prevails over others that reduce it. In this case, the calcium deficiency could be a secondary factor, increasing the risk of bitter-pit development. The presence of $\mathrm{Ca}$ could stabilize the membranes reducing their permeability; however, the high concentration of GA's would impede its movement toward the fruit. This theory is based in the fact that externally applying growth regulators that inhibit the formation of GA's the susceptibility to bitter-pit decreases independently of the Ca concentration.

The existence of these three theories is not contradictory, and possibly, the causes of the appearance of the bitter-pit are so complex that they embrace aspects of each one of the mentioned hypotheses.

In our case, a systematic study of the causes promoting bitter-pit has been initiated. As a first step, we begun to investigate the behavior of the nutrients along the vegetative cycle in two organs of the tree: leaves and fruits. For it, a plantation in which the bitter-pit appears year after year has been chosen. In this plantation, neither the treatments with Ca sprays, nor the applications of different soil fertilizers have been effective. 


\section{Materials and methods}

\subsection{Plant material}

The experiment has been carried-out in a commercial apple (Malus domestica L.) orchard of the A.L.M. Group located in Quinto de Ebro (Zaragoza, Spain), in a plot of sandy-loam soil, with $0.95 \%$ organic matter and a pH of 8.1. The orchard was subjected to the usual cultural practices of the area, including flood irrigation. The trees of cv. Golden Smoothee were grafted on MM106 rootstock and were 10-years-old at the time of the experiment.

The fertilization consisted on a complex fertilizer 15, 15, 15 (NPK) applied at a rate of $600-\mathrm{kg} \mathrm{ha}^{-1}$. In addition, four sprays of calcium chloride were applied from May to July.

\subsection{Timing of sampling}

Leaf and fruit samples were taken at 35, 56, 69, 83, 123, 144 and 157 days after full bloom.

\subsection{Sample preparation}

Leaves without the petiole and whole fruits were dried in a furnace under hot air at $60^{\circ} \mathrm{C}$ during 48 hours. They were grounded and homogenized trough a 60 mesh sieve. One and $2 \mathrm{~g}$ of leaves and fruits respectively were dry-digested in a furnace $\left(600^{\circ} \mathrm{C}\right)$ during $24 \mathrm{~h}$, and the ashes dissolved in nitric acid (1:1). The solution obtained was evaporated until total dryness and the residue was again furnaced for 1 hour at $600^{\circ} \mathrm{C}$. The ashes were dissolved by heating with diluted $\mathrm{HCl}$.

\subsection{Analysis of mineral nutrients}

The analyses for mineral elements were carried out following the methods proposed by the Comité Inter-Institutos (1969) and Pinta, M. (1973). The results were expressed as a percentage of dry matter for macroelements $(N, P, K, C a$, and $\mathrm{Mg}$ ) and as mg kg-1 of dry matter for microelements (Fe, Mn, $\mathrm{Cu}$, and $\mathrm{Zn}$ ). $\mathrm{K}$ was determined by atomic emission spectroscopy and the rest of elements except $P$ were quantified by AAS in a Unicam 929. Nitrogen was determined by 'Kjeldahl'.

\subsection{Interpretation of the analytical data}

As defined by Montañés, L. (1991) and Montañés, L. (1993), the DOP index represents the percentage deviation of the concentration of an element in the analyzed tissue with respect to the optimum content taken as the reference value. The DOP index can be calculated by the following formula:

$\mathrm{DOP}=[(\mathrm{C} \times 100) /$ Cref $]-100$ 
Where, $\mathrm{C}$ is the concentration of a given nutrient (on a dry matter basis) in the problem sample, and Cref is the optimal nutrient concentration again expressed as a percentage on a dry matter basis. As reference values for apple leaves, those mentioned by Gagnard, J. (1987) were used. Due to the lack of reference values for apple fruits several healthy apples of different varieties were acquired in the local markets (table 1). They were analyzed for mineral nutrients and after three months of cold storage, none of them showed pathological symptoms, including those of bitter-pit. Furthermore, the data obtained from the fruit analyses were in good agreement with those reported by Waller, W.M. (1980) as the optimum nutrient concentrations in apples for long term storage (table 1).

\section{Results}

An evaluation of bitter-pit incidence at harvest on the apples from the Golden Smoothee/M9 orchard showed that only few apples had symptoms, but following two months under cold storage, more than $80 \%$ were affected

It is generally accepted that fruit mineral content greatly influences storage quality and that it is possible to predict this quality from preharvest analyses of the fruit (Marcelle, R.D. (1990)).

In tables 2 and 3 , the evolution of nutrients thorough the season in leaves and fruits can be observed. Regarding the leaf macroelements, only $\mathrm{N}$ starts at the beginning of the season with a level slightly higher than in later dates. For the rest of leaf macroelements ( $\mathrm{P}, \mathrm{K}, \mathrm{Ca}$ and $\mathrm{Mg}$ ) their evolution did not followed a specific pattern of behavior.

Manganese concentration in leaf tissues decreases along the season and iron reaches a minimum value at 69 days after full bloom (DAFB) but by the end of the season (144 DAFB) almost recovered its initial value.

The leaf nutritional status was diagnosed by the DOP method, which was applied to the data corresponding to the first days of August at approximately 120 DAFB, as recommended by Conradie, W.J. (1980) for standard leaf apple sampling. This way, by comparing with the values compiled by Gagnard, J. (1987) a nutritional snapshot was obtained:

$-79 \mathrm{Mn},-50 \mathrm{Zn},-35 \mathrm{Fe},-23 \mathrm{Ca},-21 \mathrm{P}, \mathbf{2 K}, 11 \mathrm{Mg}, 14 \mathrm{~N}, 29 \mathrm{Cu} \mid 298 \Sigma_{\mathrm{DOP}} 123 \mathrm{DAFB}$

Following this sequence, it can be stated that presumably a severe $\mathrm{Mn}$ deficiency together with those of $\mathrm{Zn}, \mathrm{Fe}, \mathrm{Ca}$ and $\mathrm{P}$ occurs by this date. On the contrary, $\mathrm{Mg}, \mathrm{N}$ and especially $\mathrm{Cu}$ are in excess. In view of these results, a severe unbalanced nutritional situation of the tress can be predicted.

Applying the DOP method to the fruits at the time of harvest either using the long storage standards or the values reported by Waller (1980) (Table 1), it is clear a severe calcium deficiency in fruits together with an excess of $\mathrm{N}, \mathrm{Mg}$ and especially of $P$.

-86Ca, 7K, 17Mg, 46N, 142P $\| 307 \Sigma_{\mathrm{DOP}}$ Long Storage Standards $-53 \mathrm{Ca},-2 \mathrm{~K}, 34 \mathrm{~N}, 43 \mathrm{Mg}, 136 \mathrm{P} \| 269 \Sigma_{\mathrm{DOP}}$ Waller reference values 
Other interesting findings derived from this study were the high correlation found between nitrogen and calcium concentrations in fruits (figure 2). Analyzing all the values obtained during the season, irrespective of the date of sampling, a straight relation with a correlation coefficient of 0.961 was obtained. In the same figure, it can be observed that calcium in fruits is related, by a reciprocal equation, to the diameter of the fruits, that is to say, the smallest the caliber the highest the calcium content. Finally, it was found that soluble carbohydrates were linearly related to the leaf chlorophyll concentration measured by the SPAD (figure 3).

\section{Discussion}

In this case, post-harvest development of bitter-pit seems not to be linked with leaf potassium, since its concentration oscillates from 1.75 to 1.12 at harvest time, far enough from the value 2.2 reported by Tomala, K. (1997c) as indicator of bitter-pit risk.

In any case, it may be highlighted the difference in nutrient inputs between leaves and developing fruit, whereby the leaf nutrition is more closely related to nutrient supply from the soil, often making it difficult to establish reliable relationships between leaf minerals and fruit disorders (Ferguson, I.B. (1989)). In fact, the mineral composition of a fruit is not well correlated with leaf composition (Marcelle, R.D. (1989)).

Interestingly, the evolution of the $\mathrm{K} / \mathrm{Ca}$ ratio in fruits (table 2) seems to fit to an S-shaped curve. Until de day 69 after full bloom, remain under the value of 2530 highlighted by Waller, W.M. (1980) as the limit for important commercial losses due to bitter-pit. In our case, the ratio $\mathrm{N} / \mathrm{Ca}$ also increases its value along the season, ratio that usually correlates with K/Ca (Marcelle, R.D. (1993)) and is linked with a faster senescence.

In a similar way to that reported by Plisek, B. (1995) for Clivia apples, the relation found between fruit calcium and fruit caliber fits to a reciprocal model (figure 2), but in our case, this occurs in all the dates of the season. The highest calcium values were obtained at the first dates of sampling (table 3) corresponding with the lowest diameters measured. At these first stages, small increases in the caliber correspond to a dramatic decrease in the calcium fruit concentration. In fact, this may be due to a dilution effect, taking into account that that the time for a maximum growth, in terms of size, takes place by 56 DAFB (table 4). In fact, the fruit caliber increases from an average of $23 \mathrm{~mm}$ at 35 DAFB to $42 \mathrm{~mm}$ at 56 DAFB approximately (figure 2).

Of special interest is the almost perfect correlation found in fruits between calcium and nitrogen. This data have to be confirmed in next years experiments under different conditions, because it can means that calcium content may be a function of fruit nitrogen uptake or vice versa.

Finally, as a measure of photosynthetic performance, increases in leaf chlorophyll concentration are translated into high fruit soluble carbohydrates contents (figure 4). This is a confirmation of the transport of photoassimilates from the leaf to the fruit throughout the season. 
There is an open question about calcium deficiency in apple fruits and bitter pit development. As it has been demonstrated in this work, and in a huge amount of literature, apples affected by bitter pit contain less calcium than sound fruits. However, results obtained in our laboratory, which will be published in a future paper, confirm those already reported by Steenkamp, J. (1983), in the sense that pitted tissue contains higher concentration of calcium than the sound one. Therefore, if pitted zones accumulate calcium it is impossible that a localized calcium deficiency can induce bitter pit. The topic after one hundred years of investigation remains open and future research on the metabolic processes derived from nutritional aspects must be carried out.

\section{Acknowledgements}

This work was supported by Research Grants from the CICYT and CONSI+D (DGA)

\section{References}

1) Costa, J. Bosch, M. Blanco, A. 1995 Growth and cropping of 'Blanquilla' pear trees treated with paclobutrazol. Journal of Horticultural Science 70 433-443

2) Comité Inter-Institutos 1969 Métodos de referencia para la determinación de elementos minerales en vegetales Anales de Edafología y Agrobiología 28 403-417

3) Conradie, W.J. Terblanche, J.H. 1980 Leaf analysis of deciduous fruit trees and grapevines -summer rainfall area Fruit and Fruit Technology Researc Institute, Stellembosch H3

4) Curtis, D. Righetti, T.L. Mielke, E. Facteau, T. 1990 Mineral analysis from corkspotted and normal 'Anjou' pear fruit. Journal of the American Society for Horticultural Science 115 969-974

5) Failla, O. Stringari G. Porro, D. Scienza, A. 1993 Determination of leaf standards for apple trees and grapevines in northern Italy M.A.C. Fragoso and M.L. Beusichem (Eds) Optimization of Plant Nutrition 37-41 Netherlands Kluwer Academic Publishers

6) Ferguson, I.B. Watkins, C.B. 1989 Bitter pit in apple fruit Horticultural Reviews 11 289-355

7) Gagnard, J. 1987 Apples P. Martin-Prevel; J. Gagnard and P. Gautier (Eds.) Plant Analysis as a Guide to the Nutrient Requirements of Temperate and Tropical Crops 207-229 Lavoisier Publishers Inc.

8) Marcelle, R.D. Porreye, W. Deckers, T. Simon, P. II.Author-5:Goffings, G. II.Author-6:Herregods, M. 1989 Relationship between fruit mineral composition and storage life of apples, cv. Jonagold _Acta Horticulturae_ 258 373-378

9) Marcelle, R.D. 1990 Comparison of the mineral composition of leaf and fruit in apple and pear cultivars_Acta Horticulturae_274 315-320

10) Marcelle, R.D. 1993 Mineral nutrition and fruit quality _Acta Horticulturae $383219-225$

11) Monge, E. Val, J. Sanz, M. Blanco, A. //.Author-5:Montanes, L. 1995 Calcium as a plant nutrient. Bitter pit in apple Anales de la Estación Experimental de Aula Dei 21 189-201 
12) Montañés, L. Heras, L. Sanz, M. 1991 Desviación del óptimo porcentual (DOP):nuevo índice para la intrepretación del análisis vegetal Anales de la Estación Experimental de Aula Dei 20 93-107

13) Montañés, L. Heras, L. Abadía, J. Sanz, M. 1993 Plant analysis interpretation based in a new index: Deviation from Optimum Percentage (DOP). Journal of Plant Nutrition 16 1289-1308

14) Pinta, M. Comité Inter-Institutos (CII) 1973 Méthodes de référence pour la détermination des éléments mineraux dans les végétaux. Détérmination des élements $\mathrm{Ca}, \mathrm{Mg}, \mathrm{Fe}, \mathrm{Mn}, \mathrm{Zn}$, et $\mathrm{Cu}$ par absorption atomique. Oléagineux 28 87-93

15) Preston, A.P. Perring, M.A. 1974 The effect of summer prunning and nitrogen on growth, cropping and storage quality of Cox's Orange Pippin apple Journal of Horticultural Science 49 77-83

16) Saure, M.C. 1996 Reassessment Of the Role Of Calcium In Development Of Bitter Pit In Apple Australian Journal of Plant Physiology 23 237-243

17) Shear, C.B. Faust, M. 1980 Value of various tissue analyses in determining the calcium status of the apple tree and fruit R.A. Samish (Ed.) Recent Advances in Plant Nutrition 75-98 New York Gordon and Breach

18) Steenkamp, J. De Villiers, O.T. 1980 Gas-liquid chromatographic determination of organic acids of the Krebs cycle in apples South African Journal of Science 76 42-43

19) Steenkamp, J. Terblanche, J.H. de Villiers, O.T. 1983 The role of organic acids abd nutrient elements in relation to bitter pit in glden delicious apples Acta Horticulturae_138 35-42

20) Tomala, K. 1997a Factors affecting nutrient content and fruit quality _Acta Horticulturae 448 257-264

21) Tomala, K. $1997 \mathrm{~b}$ Predicting storage ability of 'Cortland' apples_Acta Horticulturae_448 67-73

22) Tomala, K. 1997c Effects of calcium sprays on storage quality of 'Sampion' apples_Acta Horticulturae_448 59-65

23) Waller, W.M. 1980 Use of fruit analysis D. Atkinson, J.E. Jackson, R.O. Sharples and W. Walker (Eds.) Mineral nutrition of fruit crops 383-394 London Butterworths

24) Volz, R.K. Ferguson, I. B. Bowen, J. H. Watkins, C. B. 1993 Crop Load Effects on Fruit Mineral Nutrition, Maturity, Fruiting and Tree Growth of Cox's Orange Pippin Apple Journal of Horticultural Science 68 127-137

25) Plisek, B. 1995 Development and prediction of calcium content in apples _Acta Horticulturae_383 463-474 


\section{$\underline{\text { Tables }}$}

1. Table 1. Analyses of 9 apple varieties. Data are the average of five replicates. Results and expressed in $\mathrm{g}^{100 \mathrm{~g}^{-1}}$ for macroelements and in $\mathrm{mg} \mathrm{kg}^{-1}$ for microelements, in a dry matter basis.

\begin{tabular}{l|cccccccccc} 
Variety & $\mathbf{N}$ & $\mathbf{P}$ & $\mathbf{K}$ & $\mathbf{C a}$ & $\mathbf{M g}$ & $\mathbf{F e}$ & $\mathbf{M n}$ & $\mathbf{C u}$ & $\mathbf{Z n}$ & $\mathbf{K} / \mathbf{C a}$ \\
\hline Royal Gala & 0.28 & 0.078 & 0.719 & 0.106 & 0.049 & 17.54 & 6.45 & 7.04 & 3.07 & 6.78 \\
Golden-delicious & 0.364 & 0.067 & 0.877 & 0.062 & 0.035 & 18.18 & 3.53 & 5.32 & 2.38 & 14.26 \\
Red Delicious & 0.252 & 0.063 & 0.603 & 0.074 & 0.038 & 20.45 & 3.19 & 6.55 & 1.97 & 8.20 \\
V. Doncella & 0.504 & 0.099 & 1.094 & 0.082 & 0.050 & 16.76 & 2.52 & 6.39 & 1.07 & 13.42 \\
Gloster & 0.308 & 0.064 & 0.617 & 0.086 & 0.037 & 19.18 & 4.31 & 5.46 & 1.50 & 7.17 \\
Reineta Parda & 0.532 & 0.085 & 0.936 & 0.114 & 0.040 & 25.43 & 4.15 & 8.52 & 1.72 & 8.25 \\
Fuji & 0.252 & 0.055 & 0.497 & 0.115 & 0.021 & 14.67 & 4.74 & 6.85 & 2.44 & 4.32 \\
Granny Smith & 0.308 & 0.047 & 0.696 & 0.124 & 0.028 & 25.77 & 5.44 & 5.68 & 2.06 & 5.63 \\
Reineta Blanca & 0.364 & 0.058 & 0.927 & 0.15 & 0.035 & 31.09 & 3.10 & 7.02 & 2.28 & 6.20 \\
\hline Reference value & $\mathbf{0 . 3 5}$ & $\mathbf{0 . 0 7}$ & $\mathbf{0 . 7 7}$ & $\mathbf{0 . 1 0}$ & $\mathbf{0 . 0 4}$ & $\mathbf{2 1 . 0 1}$ & $\mathbf{4 . 1 6}$ & $\mathbf{6 . 5 3}$ & $\mathbf{2 . 0 5}$ & $\mathbf{7 . 6 5}$ \\
Waller (1980) & $\mathbf{0 . 3 8}$ & $\mathbf{0 . 0 7}$ & $\mathbf{0 . 8 5}$ & $\mathbf{0 . 0 3}$ & $\mathbf{0 . 0 3}$ & & & & &
\end{tabular}

2. Table 2. Leaf nutrient concentrations along the season in dry weight basis (mean \pm standard error). $\mathrm{N}, \mathrm{P}, \mathrm{K}, \mathrm{Ca}$ and $\mathrm{Mg}$ are given in $\mathrm{g} / \mathbf{1 0 0} \mathrm{g}$, and microelements in $\mathrm{mg} \mathrm{g-1}$. Standard errors were calculated for a confidence level of $95 \%$

Days after full bloom

\begin{tabular}{|c|c|c|c|c|c|c|c|}
\hline & 35 & 56 & 69 & 83 & 123 & 144 & 157 \\
\hline $\mathbf{N}$ & $3.27 \pm 0.04$ & $3.10 \pm 0.04$ & $3.06 \pm 0.04$ & $2.83 \pm 0.03$ & $2.78 \pm 0.03$ & $2.55 \pm 0.03$ & $2.54 \pm 0.03$ \\
\hline $\mathbf{P}$ & $0.25 \pm 0.01$ & $0.31 \pm 0.01$ & $0.23 \pm 0.01$ & $0.18 \pm 0.01$ & $0.16 \pm 0.01$ & $0.20 \pm 0.01$ & $0.15 \pm 0.01$ \\
\hline K & $1.50 \pm 0.13$ & $1.51 \pm 0.13$ & $1.75 \pm 0.09$ & $1.75 \pm 0.09$ & $1.50 \pm 0.09$ & $1.12 \pm 0.09$ & $1.39 \pm 0.09$ \\
\hline $\mathrm{Ca}$ & $0.91 \pm 0.07$ & $0.77 \pm 0.07$ & $0.78 \pm 0.07$ & $0.92 \pm 0.05$ & $1.12 \pm 0.05$ & $0.95 \pm 0.05$ & $1.42 \pm 0.05$ \\
\hline Mg & $0.30 \pm 0.02$ & $0.29 \pm 0.02$ & $0.32 \pm 0.02$ & $0.36 \pm 0.02$ & $0.33 \pm 0.02$ & $0.23 \pm 0.02$ & $0.45 \pm 0.02$ \\
\hline $\mathrm{Fe}$ & $154.90 \pm 6.88$ & $123.00 \pm 6.88$ & $83.70 \pm 6.88$ & $103.70 \pm 4.86$ & $111.85 \pm 4.86$ & $130.20 \pm 4.86$ & $152.85 \pm 4.86$ \\
\hline $\mathrm{Cu}$ & $14.93 \pm 3.15$ & $12.20 \pm 3.15$ & $14.00 \pm 3.15$ & $9.95 \pm 2.23$ & $14.45 \pm 2.23$ & $7.95 \pm 2.23$ & $9.80 \pm 2.23$ \\
\hline Zn & $27.10 \pm 1.47$ & $21.30 \pm 1.47$ & $17.70 \pm 1.47$ & $19.10 \pm 1.04$ & $19.45 \pm 1.04$ & $17.95 \pm 1.04$ & $21.70 \pm 1.04$ \\
\hline Mn & $45.70 \pm 3.37$ & $37.40 \pm 3.37$ & $21.70 \pm 3.37$ & $25.75 \pm 2.38$ & $16.45 \pm 2.38$ & $43.10 \pm 2.38$ & $72.30 \pm 2.38$ \\
\hline
\end{tabular}


3. Table 3. Fruit nutrient concentrations along the season in dry weight basis (mean \pm standard error). $\mathrm{N}, \mathrm{P}, \mathrm{K}, \mathrm{Ca}$ and $\mathrm{Mg}$ are given in $\mathrm{g} / \mathbf{1 0 0} \mathrm{g}$, and microelements in $\mathrm{mg} \mathrm{g}-1$. Standard errors were calculated for a confidence level of $95 \%$

\begin{tabular}{|c|c|c|c|c|c|c|c|}
\hline & \multicolumn{7}{|c|}{ Days after full bloom } \\
\hline & 35 & 56 & 69 & 83 & 123 & 144 & 157 \\
\hline $\mathbf{N}$ & $2.30 \pm 0.03$ & $1.02 \pm 0.03$ & $0.85 \pm 0.03$ & $0.64 \pm 0.02$ & $0.48 \pm 0.02$ & $0.36 \pm 0.02$ & $0.51 \pm 0.02$ \\
\hline $\mathbf{P}$ & $0.17 \pm 0.01$ & $0.09 \pm 0.01$ & $0.09 \pm 0.01$ & $0.14 \pm 0.01$ & $0.12 \pm 0.01$ & $0.13 \pm 0.01$ & $0.17 \pm 0.01$ \\
\hline K & $1.24 \pm 0.10$ & $0.59 \pm 0.10$ & $0.67 \pm 0.10$ & $0.98 \pm 0.07$ & $0.83 \pm 0.07$ & $0.63 \pm 0.07$ & $0.83 \pm 0.07$ \\
\hline $\mathrm{Ca}$ & $0.10 \pm 0.00$ & $0.04 \pm 0.00$ & $0.03 \pm 0.00$ & $0.02 \pm 0.00$ & $0.02 \pm 0.00$ & $0.01 \pm 0.00$ & $0.01 \pm 0.00$ \\
\hline Mg & $0.11 \pm 0.01$ & $0.05 \pm 0.01$ & $0.04 \pm 0.01$ & $0.07 \pm 0.01$ & $0.06 \pm 0.01$ & $0.03 \pm 0.01$ & $0.04 \pm 0.01$ \\
\hline $\mathrm{Fe}$ & $54.50 \pm 4.02$ & $20.60 \pm 4.02$ & $25.80 \pm 4.02$ & $20.20 \pm 2.84$ & $22.00 \pm 2.84$ & $19.10 \pm 2.84$ & $18.05 \pm 2.84$ \\
\hline $\mathrm{Cu}$ & $14.40 \pm 0.75$ & $12.50 \pm 0.75$ & $5.50 \pm 0.75$ & $4.95 \pm 0.53$ & $4.05 \pm 0.53$ & $3.35 \pm 0.53$ & $4.55 \pm 0.53$ \\
\hline Zn & $26.30 \pm 1.29$ & $11.20 \pm 1.29$ & $8.10 \pm 1.29$ & $8.05 \pm 0.91$ & $5.45 \pm 0.91$ & $3.90 \pm 0.91$ & $3.35 \pm 0.91$ \\
\hline Mn & $11.40 \pm 0.49$ & $6.80 \pm 0.49$ & $4.70 \pm 0.49$ & $3.45 \pm 0.35$ & $3.30 \pm 0.35$ & $3.10 \pm 0.35$ & $2.80 \pm 0.35$ \\
\hline $\mathrm{K} / \mathrm{Ca}$ & $12.41 \pm 6.12$ & $15.52 \pm 6.11$ & $23.56 \pm 6.11$ & $46.11 \pm 4.32$ & $57.33 \pm 4.32$ & $61.38 \pm 4.32$ & $67.83 \pm 4.32$ \\
\hline $\mathrm{N} / \mathrm{Ca}$ & $22.42 \pm 3.15$ & $25.54 \pm 3.16$ & $28.84 \pm 3.16$ & $30.13 \pm 2.23$ & $33.57 \pm 2.23$ & $35.05 \pm 2.23$ & $41.43 \pm 2.23$ \\
\hline
\end{tabular}

4. Table 4. Growth parameters calculated from the curves of figure 1 following the method described by Costa, J. (1995)

\begin{tabular}{l|ccc} 
& Caliber $\mathbf{( m m})$ & Dry weight $\mathbf{( g )}$ & Fresh weight $(\mathbf{g})$ \\
\hline Max value & 81.17 & 37.91 & 234.59 \\
Time of Max Growth rate (DAFB) & 57.25 & 100 & 94.25 \\
Max growth rate (unit/day) & 0.79 & 0.42 & 2.70 \\
\hline
\end{tabular}




\section{Figures}

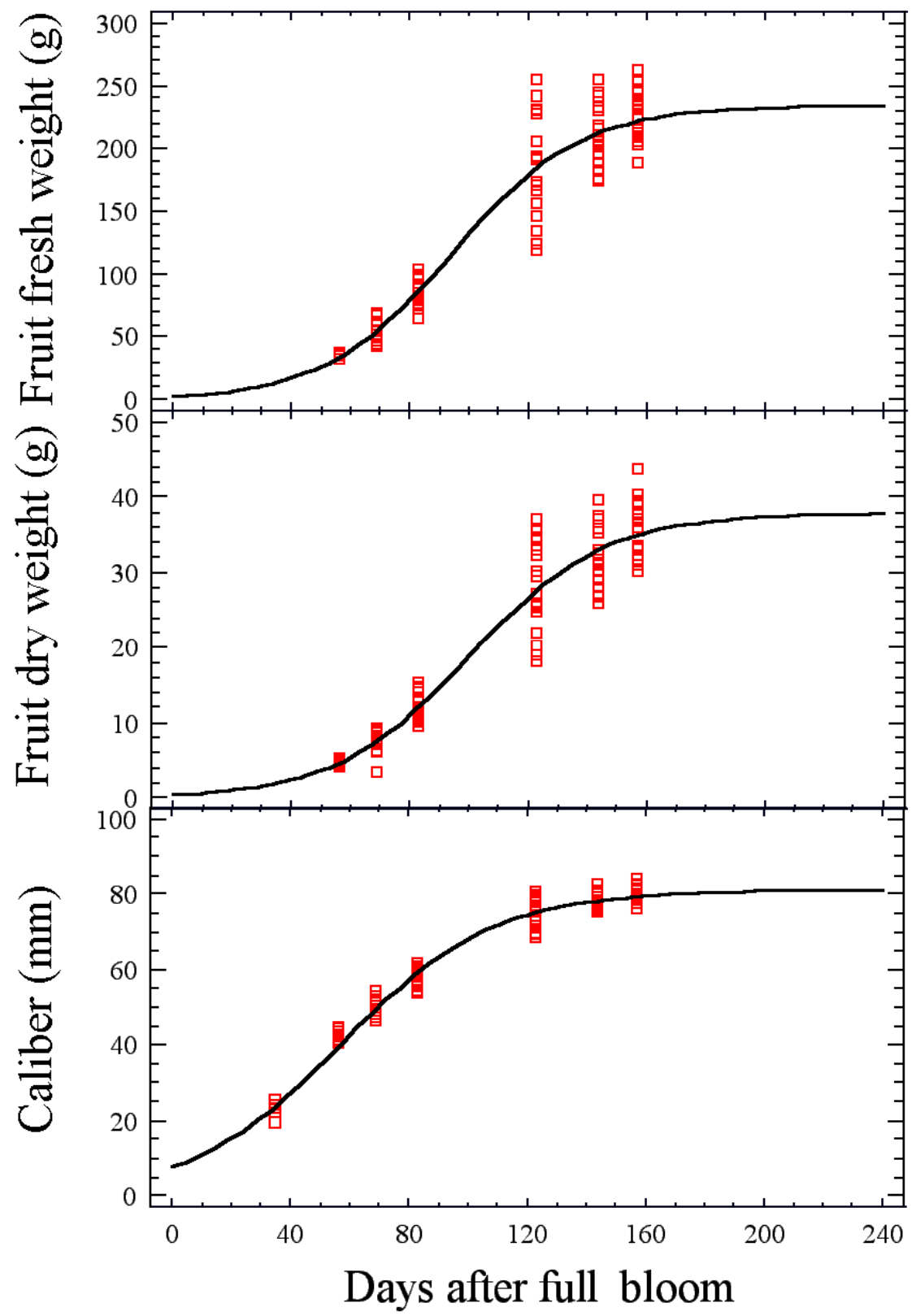

5. Figure 1. Growth development sigmoid curves corresponding to the evolution of caliber dry weight and fresh weight of fruits throughout the season. 

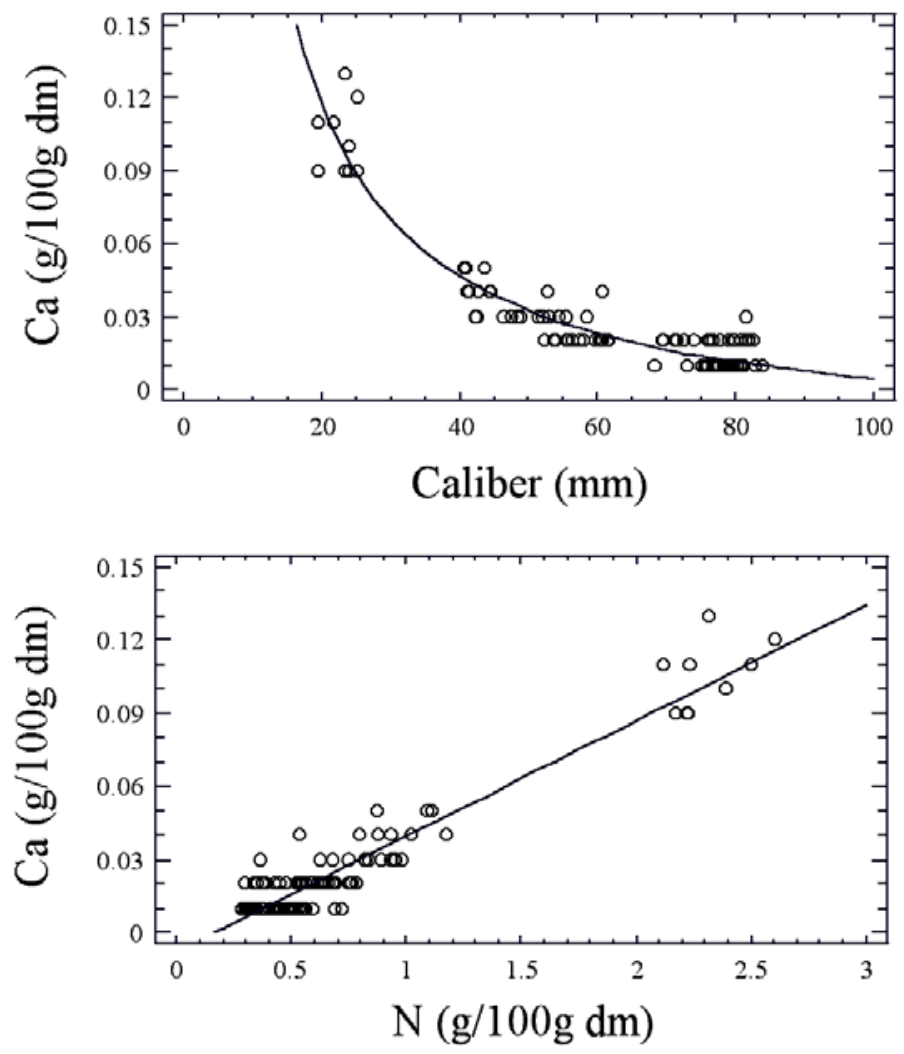

6. Figure 2. Correlations in fruit between caliber and calcium concentration, and between nitrogen and calcium. ( $\mathrm{Ca}=$ $0.0236+2.81$ caliber-1, $r=0.957 ; \mathrm{Ca}=-0.0078+0.0474 \mathrm{~N}, \mathrm{r}=0.961$; $\mathrm{p}=0.0001)$

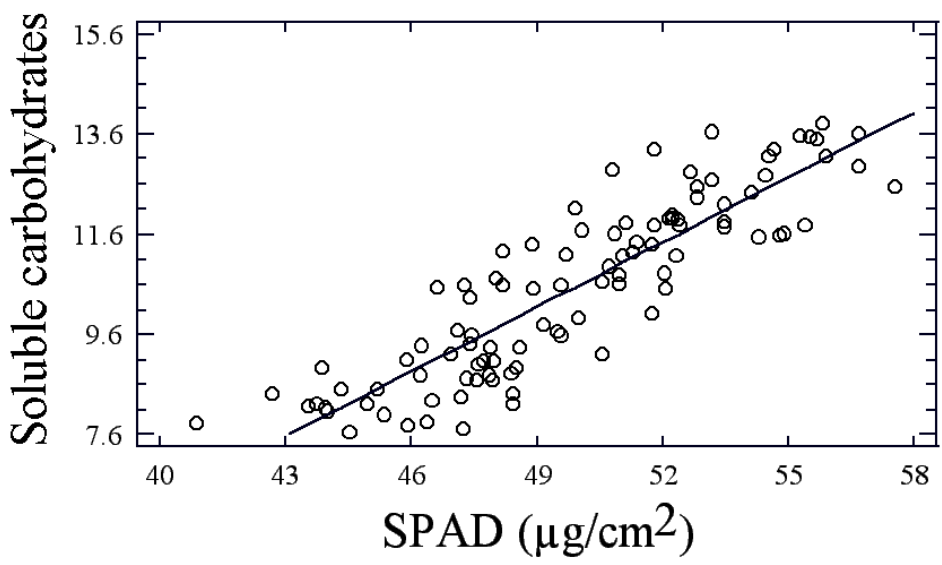

7. Figure 3. Linear relation between total chlorophyll measured by SPAD and soluble carbohydrates. Carbohydrates $=-10.978+0.431$ SPAD. $(r=0.88 ; p=0.0001)$ 